\title{
EXPERIMENTAL DATA ACQUISITION OF VIBRATION FORCE IN DIRECT CURRENT MOTOR FOR MINI SUMO ROBOT
}

\author{
Ali Sinan Cabuk \\ Electrical Engineering Department, Electrical \& Electronics Engineering Faculty, \\ Istanbul Technical University, Turkey \\ ITU Ayazaga Campus, 34469 Maslak, Turkey \\ phone/ mobile: +902122856779, +905353452165, e-mail: ascabuk@itu.edu.tr
}

\begin{abstract}
Vibration is the oscillating or periodic movement of electric motors from its position to a certain point, which has effect on performance. The vibration of electrical motor is essential causes of machine failure. Therefore, reaction force of electric motors is the most important parameter for their working life. It is monitoring and minimize the vibration generated by the electric motor. One of the objectives of this study is to present that forced vibration analysis is compatible technique for diagnosing electromagnetic and mechanical problems in electric motors. In this study aims at vibration analysis on Direct Current (DC) motor, that is the most preferred motors for robotic application. DC motor used in this study has $15 \mathrm{~W}$ output power, $400 \mathrm{~min}^{-1}$ shaft speed and $12 \mathrm{~V}$ terminal voltage, which is widely implemented in robot competition. Vibration forced was measured with accelerometer sensor on the motor. Test vibration results of the motor were checked it whether limiting value or not. In this study, vibration effect of DC motor in mini sumo robot is presented with during competition and smooth road conditions.
\end{abstract}

Keywords: Vibration, DC motor, Arduino, Accelerometer, Mini Sumo.

\section{INTRODUCTION}

Direct Current (DC) motors are used industrial application and robot technology, which are basic controller and can be more various as size. Robotic systems require a high inrush torque and speed. The DC motor has a great torque vs. speed characteristic. In addition, DC motors are an ideal way of achieving the miniaturization that is so desirable to designers. Because of the fact that these properties many manufacturer prefer DC motor for robotic applications [1-3].

A mechanical commutator is used to transmit input current into their armature windings by DC motors. The process contains the sliding contacts between carbon brushes on stator and ring of copper segments on armature. The segments are called bars, which connect to winding. Thus input current transmits from brushes to armature windings. Input current flows to one of bars with each brush. The bars are connect to coils in the armature winding. When the armature rotates in the motor, the coils are interrupted and reversed as periodically. Hence ripple voltage and cogging torque show up at the same time. Cogging torque generates vibration force on the motor. The force can be destructive effect on the DC motor and their components. Vibration forces created by DC motors used in mini sumo robots have negative effects on the parts connected to them. Therefore it is critical to analyse the effects of the vibration forces created by these motors [2-8].

Sumo robot is among the world wide favourite tournament classifications of robot competitions. Sumo wrestlers in Japan inspired the creators of Sumo robots. The competition can be simply described as two sumo robots attempting to push their opponent out of the arena. The arena is in the shape of a circle just as the original arena used for sumo wrestling. The colours of the arena are black and white, with a white circle around the arena

IRTIIE Vol. 7, No. 1, 2019 ISSN 1314-8788 (print), ISSN 1314-8796 (online), doi: 10.15547/artte.2019.01.006 


\section{ARTTIE $Y$}

Ipplied Resseirl'hes in Technics, Technologies and Bductition

Journal of the Faculty of Technics and Technologies, Trakia University https://sites.google.com/a/trakia-uni.bg/artte/

and black surface on the inside. Sumo tournaments generally have common rules however every robot competition can have its own rules. Generally, sumo robot games are three rounds. Winning two out of the three rounds defines the leader robot. In the beginning of a match, two opponent robots are placed on the arena facing the opposite sides. After they are turned on, the robots are supposed to start moving after 5 seconds. The design of sumo robots are made so that they do not damage their opponents or any part of the arena. In case any part such a sticker or spacer falls off from a sumo robot, then it will be disqualified [8-11].

Dimensions of sumo robots define the category in which they fall; from the smallest size to the biggest, they are defined as mini sumo, micro sumo, nano sumo, heavy Japanese sumo and standard sumo. Mini sumo was used in this study. Using the most commonly used sensors which are infrared sensors, Mini sumo robot is capable of following the white path of the arena, detecting its opponent and being autonomous [9].

The propulsion part makes the most important component of the sumo robot. In propulsion of the robot frequently DC motors are used. The most critical parameters of the motor are torque and speed. Harmony between the motor and the main structure is the other significant parameter. The robot will not work properly in case the motor is not connected to harmony. As a result of not being connected to harmony the robot will not move and therefore lose in the competition.

One of the most important reasons for motor failure is the vibration of DC motor and it is not acceptable in precision motion control. Vibration of the motor must be detected and prevented; otherwise it causes damage to the propulsion part of the robot [2].

\section{MATERIAL AND METHODS}

Vibration is continuous and repeated occurrence. Most of vibrations are not required in motors and part of the motor and they can be destructive effect on the motor. Nonetheless vibration force can be decreasing of bearing life, reason of increased stresses, induce fatigue, energy losses, wear of parts of motor and absorb energy from the mechanism. Vibration can be measured by three different magnitude. These are acceleration (a), displacement (d) and velocity (v). Vibrations per minute (vpm) is often expressed for rotating machinery as shown Equation (1).

$$
V P M=\omega / \pi
$$

Where $\omega$ is angular velocity. Acceleration is defined as the time rate of change of velocity and is expressed in units of meter per second squared. Vibration frequencies above $1000 \mathrm{~Hz}$ should always be expressed as acceleration. Acceleration is commonly expressed in terms of the gravitational constant, $\mathrm{g}$, which is $32.17 \mathrm{ft} / \mathrm{sec}^{2}$. In vibration analysis applications, acceleration is typically expressed in terms of $\mathrm{g}-\mathrm{RMS}$ or $\mathrm{g}-\mathrm{PK}$. These are the best measures of the force generated by a machine, a group of components, or one of its components [12-14]. A simple harmonic oscillation can determine these measurement units. There are two methods, that are usually used to determine vibration. One uses the estimated value from the voltage and the other benefits from an acceleration sensor mounted on the motor case. In this condition the acceleration is measured gives the value of vibration [2].

The forced vibrations have an impact many times on mini sumo robot mechanism during competition. The sensor module can be calculated the radial and tangential magnetic force with the following equations:

$$
F_{r}=K b h E \varepsilon_{r}
$$

IRTIIE Vol. 7, No. 1, 2019 ISSN 1314-8788 (print), ISSN 1314-8796 (online), doi: 10.15547/artte.2019.01.006 


\section{IRTIIE}

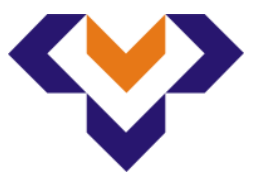

Ipplied Resseirl ches in Technics, Technologies and Bductition

Journal of the Faculty of Technics and Technologies, Trakia University https://sites.google.com/a/trakia-uni.bg/artte/

$$
F_{\theta}=\left(\left(b h^{2} E\right) / 6 I\right) K \varepsilon_{\theta}
$$

where $K$ is coefficient, $b$ is thickness, $E$ is Young's modulus, $\varepsilon$ is strain, $h$ is pole width and $I$ is distance between load point and sensing point [16]. Radial and tangential magnetic force of mini sumo robot are calculated by MPU 6050 (Sensor module). The force data are transferred to computer by Ardunio Uno.

An acceleration sensor is the most important part to measure vibration forced. An accelerometer is a detector unit that measures the forced of vibration. Besides it can measure acceleration of motion of a movement. The vibration produces this force, then the force cause a change in movement. An acceleration can cause to be the mass to load the piezoelectric material that generates an electrical charge that is proportional to the force applied on them. A load is directly related to the force. Moreover the mass of motor is constant value. Consequently, the load is proportional to the acceleration. In many sensors, the forces on the surface of the motor is result of the applied mechanical load as a mass force. Generated Electrical signals from piezoelectric material oscillate in specific frequency range. The signal has occurred from Newton's law of motion. That means the induced charge directly depend on the applied mass load. Crystals in sensor generate the electrical signal and transmit over an electronic device part of the sensor, then reached to measurement device.

Accelerometers have a lot of advantages. They can be classified according to their properties such as response to level of frequencies, design ability, working conditions etc. Also they have some disadvantages. They are not sensitive under high frequency noise, they can need an external power supply and electronic integration is necessary as FET transistor integration. Due to these characteristics, acceleration sensor is preferred in this study for measure vibration force.

In this study, vibration characteristics of DC motor in mini sumo robot was measured with acceleration sensor with Arduino Uno, which was presented. The selected motor and measured equipment are shown in Fig.1, and motor data is given in Table 1. The motor has a shaft to be connected to the reductor.

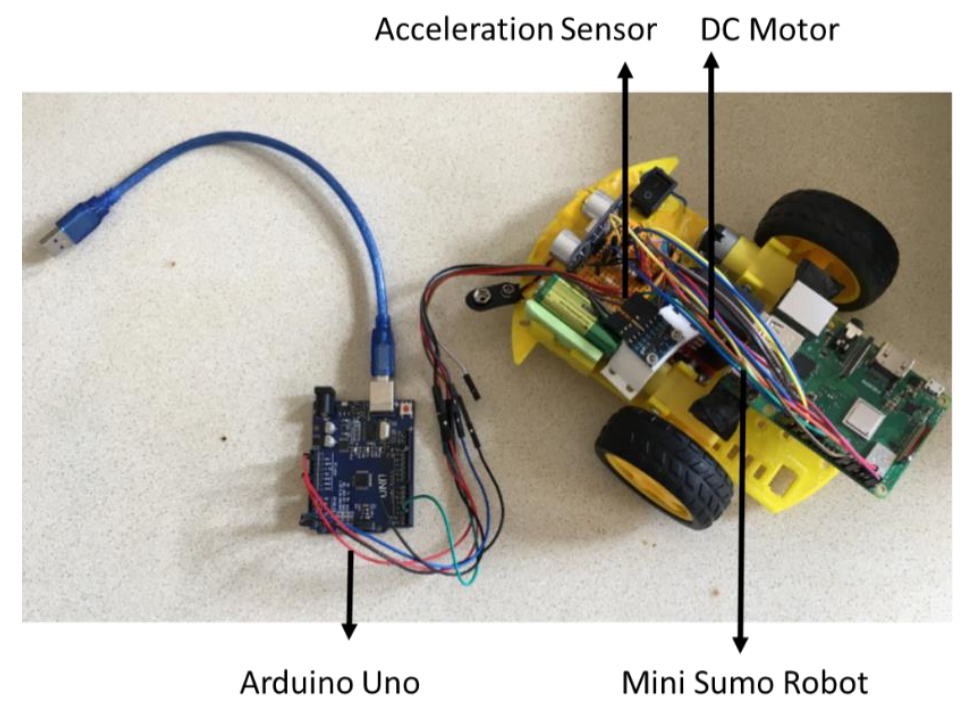

Figure 1. Equipment's of experiment 


\section{IRITIE Ipplied Researrches in Technics, Technologies and Educition Journal of the Faculty of Technics and Technologies, Trakia University https://sites.google.com/a/trakia-uni.bg/artte/}

Table 1. DC motor data in experiment

\begin{tabular}{|c|c|}
\hline Parameter & Value \\
\hline Voltage $[\mathrm{V}]$ & 12 \\
\hline Power $[\mathrm{W}]$ & 15 \\
\hline Rated Speed $\left[\mathrm{min}^{-1}\right]$ & 400 \\
\hline Diameter of Motor $[\mathrm{mm}]$ & 34 \\
\hline Weight of Motor $[\mathrm{kg}]$ & 0.180 \\
\hline Weight of Motor with Reductor $[\mathrm{kg}]$ & 0.326 \\
\hline
\end{tabular}

Test equipment was arranged for data acquisition from DC motor in mini sumo robot, before the vibration test. Table 2 shows the equipment of the experiment. The vibration test was employed procedure by using the following equipment's:

- Arduino Uno unit was used for data acquisition and processing with a $16 \mathrm{MHz}$ resonator, which has inputs/output pins as 14 digital and 6 analogue.

- MPU-6050 is Three Axis Gyro with accelerometer sensor, which was used for measure the vibration of motor, that has 16 bit analogue to digital converter-chip and 16-bit data output.

- 12V. DC motor with gearbox for actuating mechanism.

Table 2. Equipment of the experiment

\begin{tabular}{|c|c|c|}
\hline Components & Description & Image \\
\hline Vibration & $\begin{array}{c}\text { 3 Axis Acceleration } \\
\text { Sensor Module }\end{array}$ \\
\hline Microcontroller & Arduino Uno & \\
\hline Motor & 12V. DC Motor & \\
\hline
\end{tabular}

Inertia Measurement Unit (IMU) sensors generally has at least two parts. These parts can be listed by the order of importance as gyroscope, accelerometer, altimeter and magnetometer. The MPU 6050 has two different IMU sensor and each sensor has three axis IMU sensor, which gives six output values. First three values come from the gyroscope, the other three values come from the accelerometer. The MPU 6050 sensor is based upon Micro Electro Mechanical Systems (MEMS) technology. The gyroscope and the accelerometer are both embedded in the same chip. Inter Integrated Circuit (I2C) protocol is used in the chip as communication $[11,15]$.

An accelerometers base on the principle of piezo electric effect, which are like a small ball inside a cuboidal box. Piezo electric crystals are used to make up the walls of the box. Due to gravity, when the box is tilted, the ball moves in the direction of the slope. The ball collides with the walls and produce low piezo electric currents. There are three pairs of opposite balls in a cuboid in total. Each pair corresponds to one of these axises in 3D space: $\mathrm{X}, \mathrm{Y}$ and $\mathrm{Z}$. The direction of inclination and its magnitude are determined according to the low-current generate from piezo electric walls. 


\section{IRTITE}

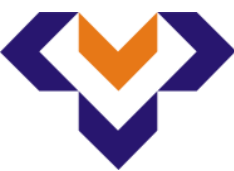

Ipplied Resseirl'hes in Technics, Technologies and Bductition

Journal of the Faculty of Technics and Technologies, Trakia University https:///ites.google.com/a/trakia-uni.bg/artte/

The MPU 6050 is used to communicate with Arduino by the Inter Integrated Circuit (I2C) protocol. The connection of MPU 6050 to the Arduino with a 5V pin, MPU 6050 module can be connected to the $5 \mathrm{~V}$ pin of Arduino. Otherwise it needs to be connected to a $3.3 \mathrm{~V}$ pin. Then, ground (GND) terminal of the Arduino needs to be connected to a ground (GND) terminal of the MPU 6050. The software we are using also benefits from the Arduino's interrupt terminal pin. Therefore, Arduino's digital pin 2 should connect to interrupt pin on the MPU 6050. Afterwards the I2C lines need to be set up. In order to do this, firstly the SDA pin of the MPU 6050 needs to be connected to the Arduino's analog pin as number 4. After that, the SCL pin of the MPU 6050 needs to be connected to the Arduino's analog pin as number 5 [15].

The main scheme of the test setting with the mini sumo robot is given in Figure 2. The Figure 3 shows the photograph of the test setting.

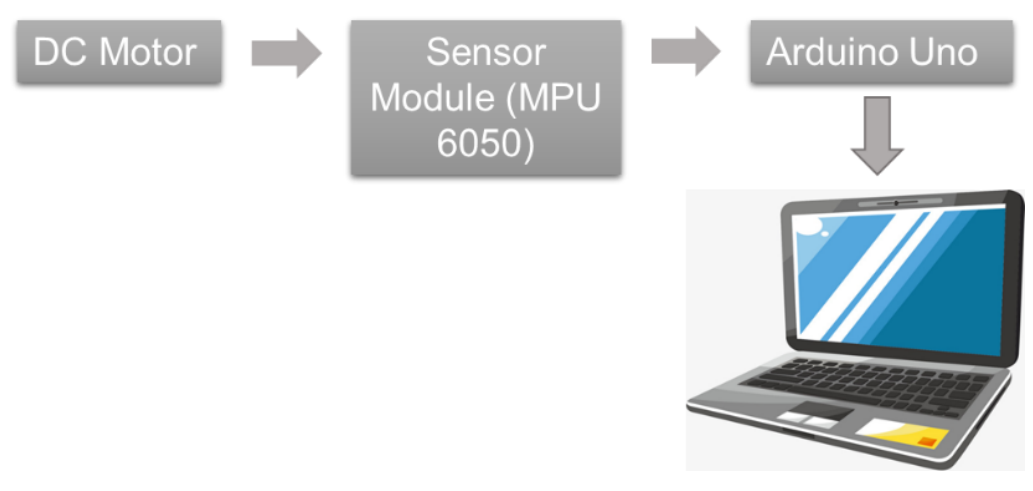

Figure 2. Block diagram of overall

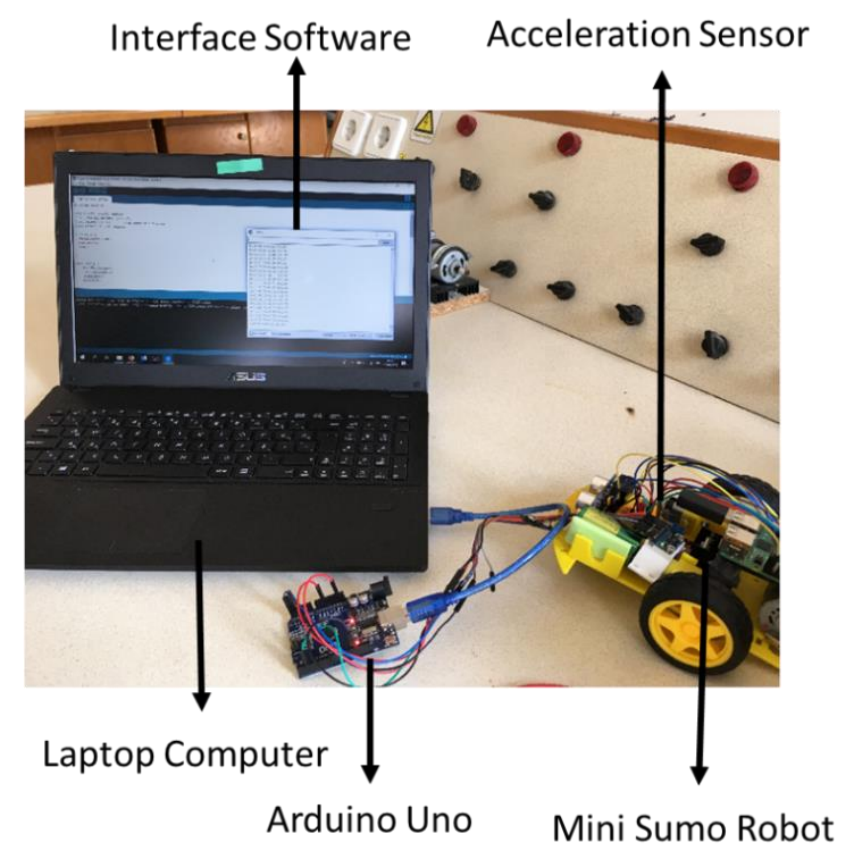

Figure 3. Test Bench

IRTIIE Vol. 7, No. 1, 2019 ISSN 1314-8788 (print), ISSN 1314-8796 (online), doi: 10.15547/artte.2019.01.006 


\section{ARTIIL \\ ( \\ Ipplied Resseirlohes in Technics, Technologies and Bductition \\ Journal of the Faculty of Technics and Technologies, Trakia University https://sites.google.com/a/trakia-uni.bg/artte/}

\section{RESULTS AND DISCUSSION}

Before the vibration force test, DC motor on the mini sumo robot verified by vibration test. For this purpose the wheels of mini sumo robot was hung in the air with wheel jack as shown Figure 4. Because of the fact that the superior precise sensitivity measurement necessity, all the test equipment's are designed, calibrated and assembled exactly.

The vibration force of motor was measured with smooth road condition, it means the mini sumo robot is not competitive and will have to lose. The DC motor does not generate vibration on the road condition and almost has a smooth waveform. Figure 5 shows the measured values of the reaction force vs. time.

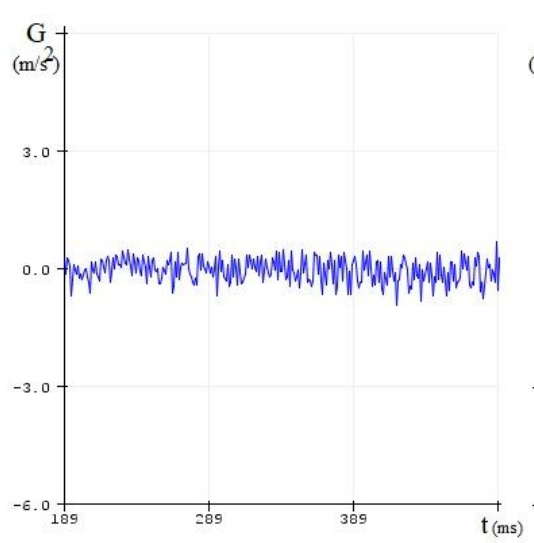

(a)

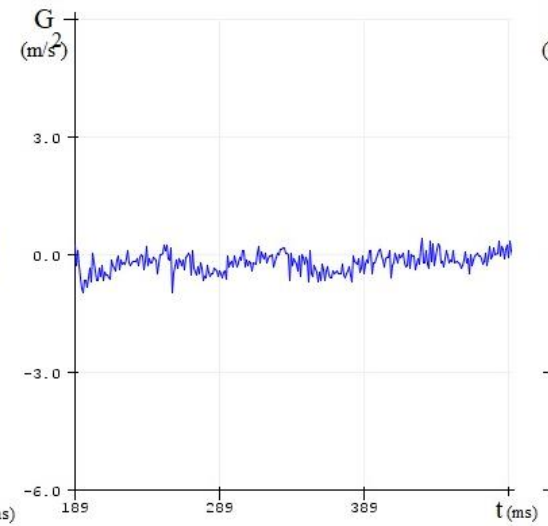

(b)

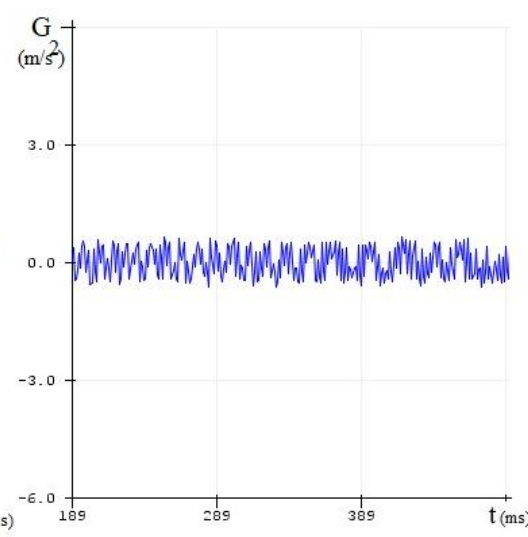

(c)

Figure 4. Waveform of reaction force versus time performed no-drive mode for (a) $x$ axis, (b) y axis, (c) $z$ axis

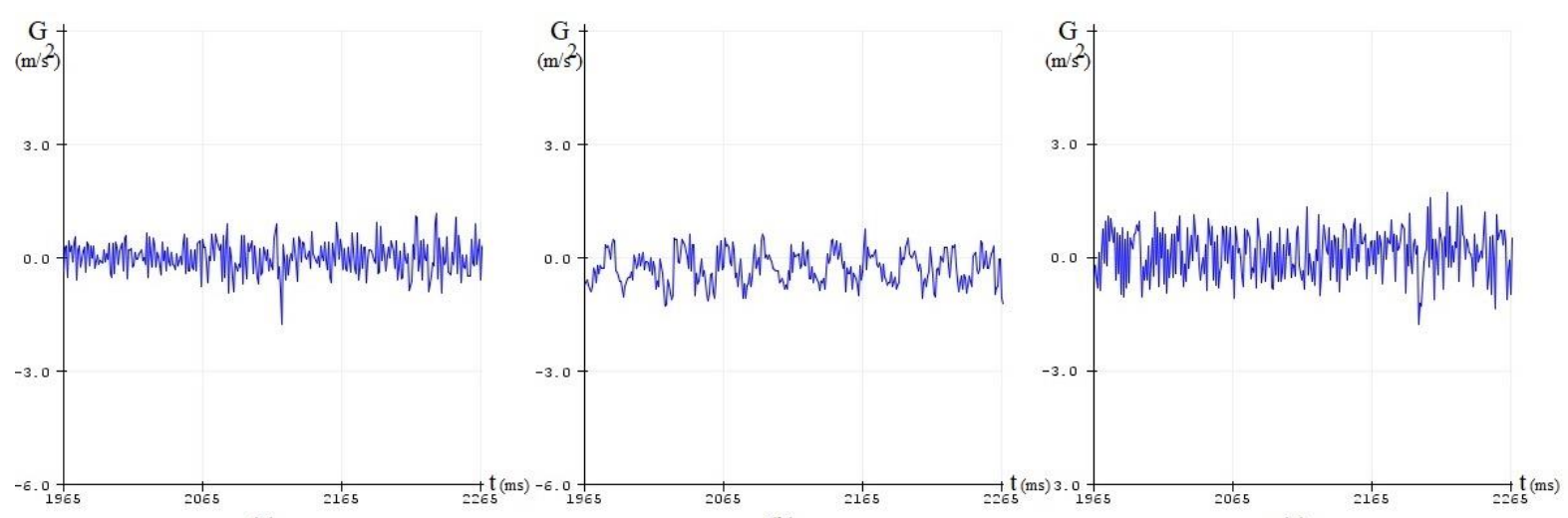

(a)

(b)

(c)

Figure 5. Waveform of reaction force versus time performed during on road for (a) $x$ axis, (b) y axis, (c) $z$ axis

Other phase of measurement; Analysing the vibration forces created by the DC motor during the competition of the mini sumo robots. During the competition, the changes in vibrations on the mini sumo robot were observed to be no longer linear and distortions were observed specifically at moments of collisions. Vibrations forces created during impact or collision with the competitors for on $\mathrm{x}, \mathrm{y}$ and $\mathrm{z}$ axis's are showing Figure 6.

IRTIIE Vol. 7, No. 1, 2019 ISSN 1314-8788 (print), ISSN 1314-8796 (online), doi: 10.15547/artte.2019.01.006 


\section{ARTTIE $Y$}

Ipplied Resseirl'hes in Technics, Technologies and Bductition

Journal of the Faculty of Technics and Technologies, Trakia University https://sites.google.com/a/trakia-uni.bg/artte/

As shown Figure 5, forced vibration is in the limiting value during on road condition for $x, y$ and z-axis. The condition means there is no any impact on the DC motor and mini sumo. Forced of vibration is not influential as destructive both mechanical part of mini sumo robot and housing of DC motor. As it can be seen Figure 6, forced vibration during in competition is higher than during road condition for $\mathrm{x}, \mathrm{y}$ and $\mathrm{z}$-axis. The value peaks moment of collision. The reaction force is around $5 \mathrm{~m} / \mathrm{s}^{2}$ for x-axis, $4 \mathrm{~m} / \mathrm{s}^{2}$ for $y$-axis and $4 \mathrm{~m} / \mathrm{s}^{2}$ for $z$-axis.

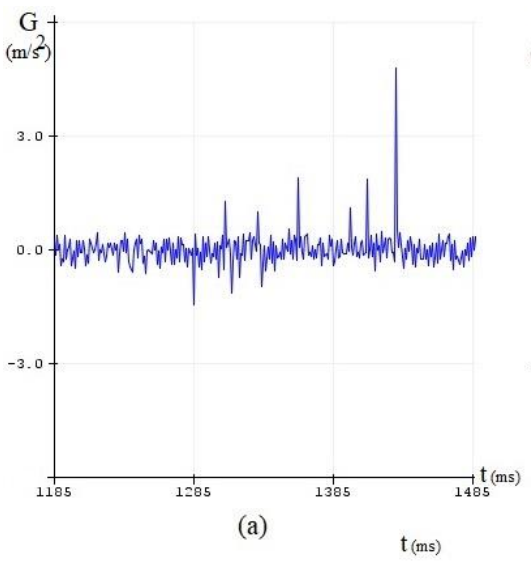

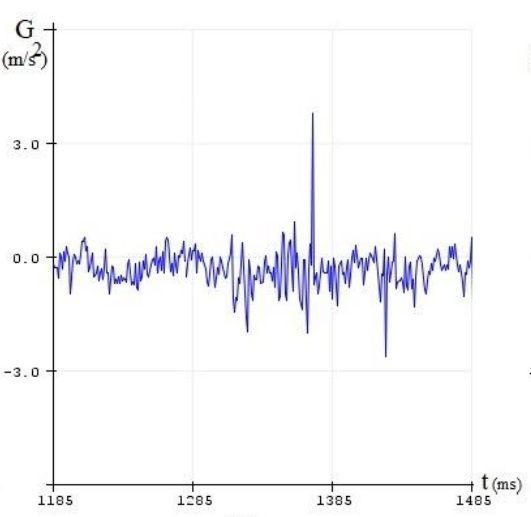

(b)

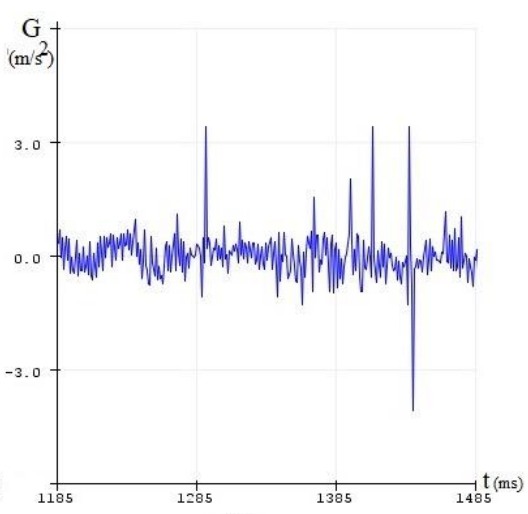

(c)

Figure 6. Waveform of reaction force versus time performed during in competition for

(a) $x$ axis, (b) y axis, (c) $z$ axis

The values of vibration force for different conditions results are compared in Figure 7,8 and 9. It can be seen all values on the motor as xyz axis for sampling time. Sampling time was used as 20 consecutive steps. Besides during this study, it was attention an external vibration as shake in test bench. The test bench was prevented from vibrating. Thus more accurate results have been obtained.

Figure 7 indicates comparison of reaction force for $x$ axis. It should be seen reaction force is the higher during competition than other condition, but peak value of reaction force have occurred collision times. First collision can be seen around $800 \mathrm{~ms}$ as small effect. Strong effect is around $2000 \mathrm{~ms}$ as around $5 \mathrm{~m} / \mathrm{s}^{2}$.

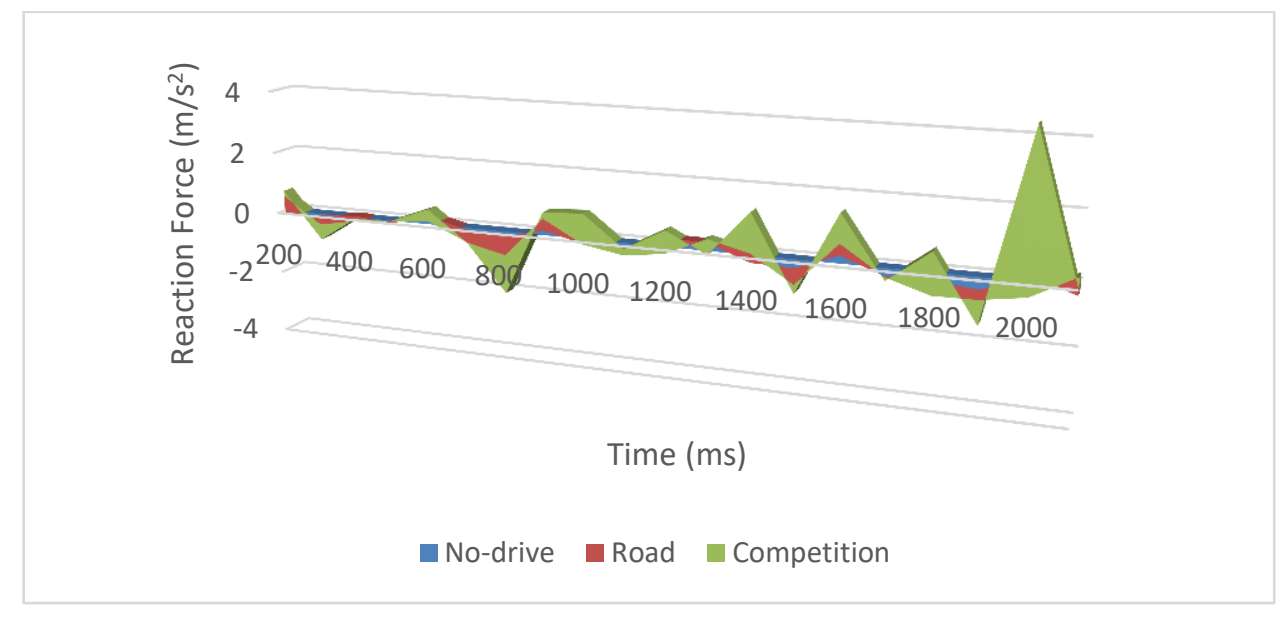

Figure 7. Comparison of reaction force for $\mathrm{x}$-axis

IRTIIE Vol. 7, No. 1, 2019 ISSN 1314-8788 (print), ISSN 1314-8796 (online), doi: 10.15547/artte.2019.01.006 


\section{IRTTIE

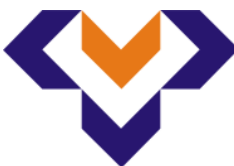

Ipplied Resererthes in Technics, Technologies and Bduration Journal of the Faculty of Technics and Technologies, Trakia University https:///ites.google.com/a/trakia-uni.bg/artte/

In Figure 8, it can be seen reaction force are much higher than others. Strong damage can occur on the motor and components.

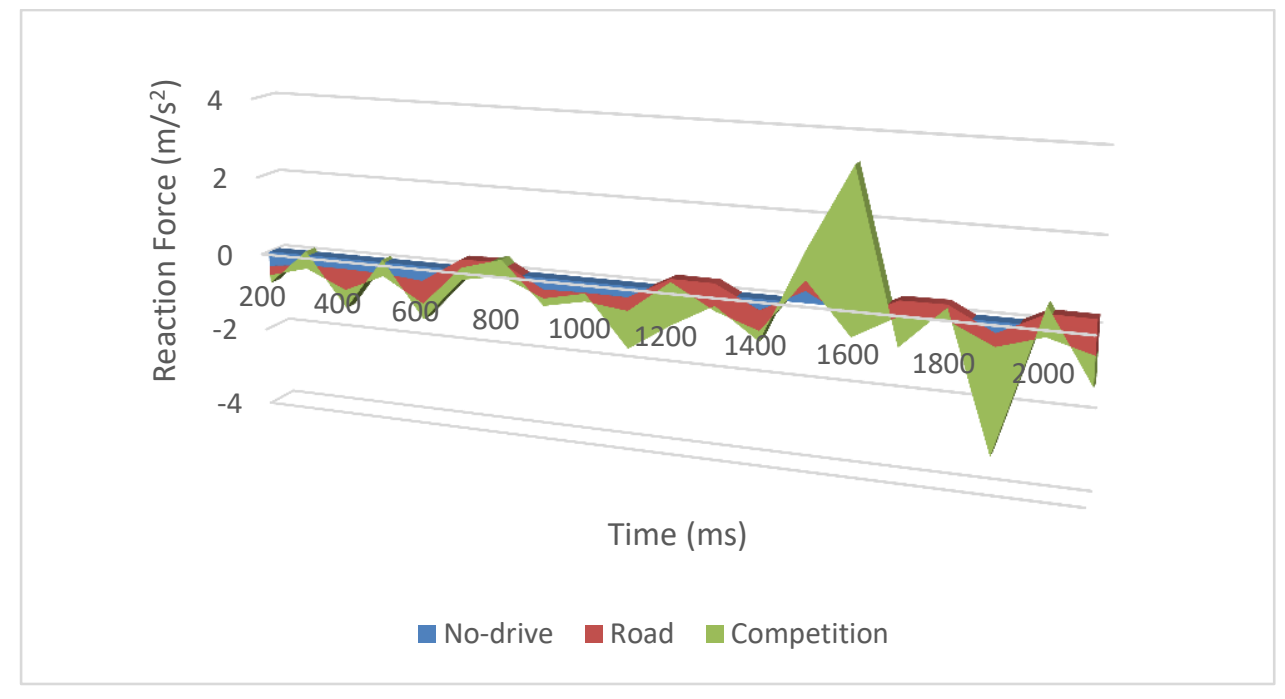

Figure 8. Comparison of reaction force for $y$-axis

As shown Figure 9, strong effect is around $800 \mathrm{~ms}$ as different from other axis. Other effects of reaction force is the same $x$ and $y$-axis.

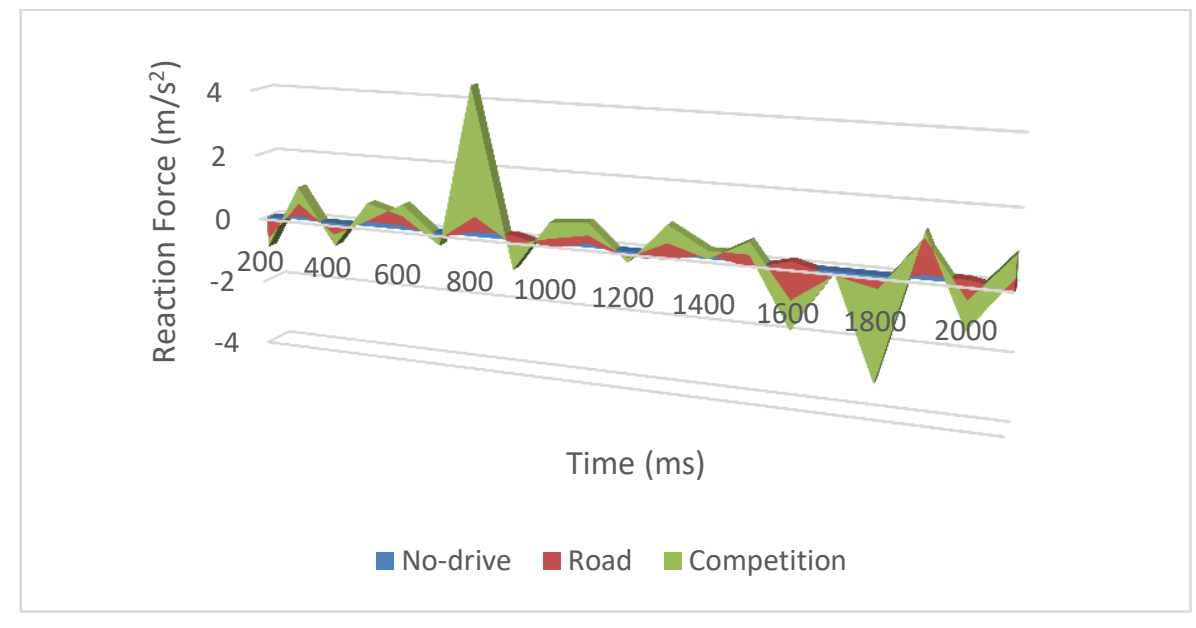

Figure 9. Comparison of reaction force for z-axis

\section{CONCLUSION}

This paper has presented data acquisition of vibration force in direct current motor for mini sumo robot by by Ardunio Uno. Vibration force is one of the most important parameters, which has effect on performance of the electric motor. If the forced vibration of electric motor was not prevented, it can be major causes of machine failure. Also electrical motor vibration is unacceptable in more precision motion control. For this reason, it is essential to analyse and minimize the vibration generated by the electric motor. Consequently, vibration force characteristics of DC motor for mini sumo robot were analysed. In order to conduct such analysis vibration of the DC motor was measured with acceleration sensor with Arduino Uno.

IRTIIE Vol. 7, No. 1, 2019 ISSN 1314-8788 (print), ISSN 1314-8796 (online), doi: 10.15547/artte.2019.01.006 


\section{ARTTIE $Y$}

Ipplied Resseirlohes in Technics, Technologies and Bductition

Journal of the Faculty of Technics and Technologies, Trakia University https://sites.google.com/a/trakia-uni.bg/artte/

Moreover DC motor used in this study has $15 \mathrm{~W}$ output power, $400 \mathrm{~min}^{-1}$ shaft speed and 12 $\mathrm{V}$ terminal voltage. Test vibration force results of $D C$ motor in mini sumo robot were checked it whether limiting value or not. Under smooth road conditions there were not observed any destructive vibration forces on the connections of DC motor to the mini sumo robot or mechanical parts. During the moment of competition when mini sumo robot was in contact with other robots, vibration forces affecting the mechanical parts were observed to increase. However this increase was concluded not to have any destructive effect on the measured values. It was found that the induced vibration of DC motor in mini sumo robot results as xyzaxis.

This study is important in terms of giving importance to vibrations for researchers performing mini sumo robot manufacturing. Also highlights the importance of mounting mechanical parts to reduce vibrations.

Further experimental investigations and studies on vibration of robotic area can need to results of this study for damping to vibration on motors and their equipment's.

\section{REFERENCES}

[1] Jackson J. (2007). Microsoft robotics studio: A technical introduction. IEEE Robotics \& Automation Magazine, Vol. 14 (4), 2007, pp. 82-87.

[2] Ito T. \& Akatsu K. (2016), Electromagnetic force acquisition distributed in electric motor to reduce vibration. IEEE Transactions on Industry Applications, Vol. 53, Issue 2, 2016, pp. 1001-1008.

[3] Diveev A. I. \& Ibadulla S. I. (2018). Evolutional methods for creating artificial intelligence of robotic technical systems. Applied Researches in Technics, Technologies and Education Journal of the Faculty of Technics and Technologies, Vol. 6, No. 2, 2018, pp. 148-152.

[4] Kia S. H. \& Razavi-Far R., Saif T. M. (2018). Torsional Vibration Identification Using Electrical Signatures Analysis in Induction Machine-Based Systems. IEEE 61st International Midwest Symposium on Circuits and Systems (MWSCAS), Windsor, Canada, 5-8 Aug., 2018, pp. 813-816.

[5] Boglietti A., Cavagnino A. \& Tenconi A. (2012). Low cost solutions to reduce cogging torque and acoustic noise of small brushed DC motors for automotive radiator cooling fan modules. IEEE IECON Conf., Montreal (Canada), 25-28 October, 2012, pp. 18701876.

[6] Sun T., Kim J. M., Lee G. H., Hong J. P. \& Choi M. R. (2011). Effect of pole and slot combination on noise and vibration in permanent magnet synchronous motor, IEEE Trans. Magn., 47 (5), 2011, pp. 1038-1041.

[7] Chaudhari Y. K., Gaikwad J. A. \& Kulkarni J. V. (2014). Vibration analysis for bearing fault detection in electrical motors. First International Conference on Networks \& Soft Computing (ICNSC2014), Guntur, India, 19-20 Aug., 2014, pp. 146-150.

[8] Suriano J. \& Ong C. M. (1989). Modeling of Electromechanical and Electromagnetic Disturbances in DC Motors. Conf. Rec. IEEE National Symposium on Electromagnetic Compatibility, Denver, USA, 23-25 May, 1989, pp. 258-262.

[9] Tirian O., Nitescu A. \& Chioncel C. (2015). The design and construction of an autonomous mobile mini-sumo robot. Acta Tehnica Corviniensis - Bulletin Of Engineering Tome VIII, Faculty of Engineering - Hunedoara, University Politehnica Timisoara, 2015.

[10] Cervera E., Garcia J. C. \& Sanz P. J. (2015). Toward the Robot Butler: The HUMABOT Challenge, IEEE Robotics \& Automation Magazine, Vol. 22 (2), 2015, pp. 8-17. 


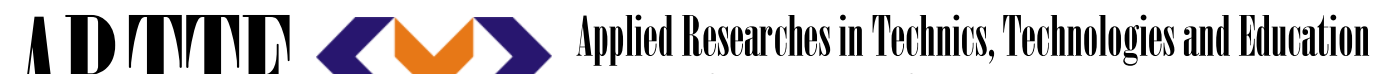 Journal of the Faculty of Technics and Technologies, Trakia University https://sites.google.com/a/trakia-uni.bg/artte/}

[11] Ghosh A. M., Halder D., \& Hossain S. K. A. (2016). Remote health monitoring system through loT. 5th International Conference on Informatics, Electronics and Vision ( ICIEV 2016), Dhaka, Bangladesh, 13-14 May, 2016, pp. 921-926.

[12] Mobley R. K. (1999). Vibration Fundamentals. Butterworth-Heinemann, United States of America, 1999.

[13] Mobley R. K. (1999). Root Cause Failure Analysis. Butterworth-Heinemann, United States of America, 1999.

[14] Mobley R. K. (1999). Maintenance Fundamentals. Butterworth-Heinemann, United States of America, 1999.

[15] Arduino 6050-IMU sensor tutorial. Available: https://maker.pro/arduino/tutorial/how-to-interface-arduino-and-the-mpu-6050-sensor [08.01.2019].

[16] Ito T. \& Akatsu K. (2015). Electromagnetic Force Acquisition Distributed in Electric Motor to Reduce Vibration. 2015 18th International Conference on Electrical Machines and Systems (ICEMS), Pattaya City, Thailand, Oct. 25-28, 2015, pp. 1329-1333. 